\title{
Abstract: Magical Repute (The Explicit and Implicit Effect of Corporate Brand Reputation on Brand Attachment)
}

\author{
Klaus-Peter Wiedmann, Steffen Schmidt, Sascha Langner, Philipp Reiter, \\ Levke Albertsen, and Evmorfia Karampournioti
}

\begin{abstract}
In both marketing research and business practice, the study of corporate brand reputation has gained growing interest. Especially, the highly dynamic and intense contentions in the various markets worldwide initialized a paradigm shift from physical competition, including tangible problem solutions and overall product quality, to a psychological competition with reference to identity and reputation. However, better knowledge of drivers of corporate brand reputation, and the effects on the overall brand performance from a customer's perspective, is still needed. That said, previous studies about corporate brand reputation fall back on traditional and basic explicit self-reporting scales. However, an increasing number of neuroeconomic studies indicate that customers are not fully aware of their thoughts and opinions. In fact, most mental processes are of so-called implicit nature, taking place hidden in the unconscious and automatic mind. Yet, established models of corporate brand reputation are missing implicit processes completely. Against this backdrop, the aim of the current paper is to fill this research gap. For that reason, a holistic framework of dual information processing is derived with reference to corporate brand reputation. Furthermore, related explicit (reflected/deliberate) and implicit (impulsive/automatic) measures are developed and applied to capture the dual facets of corporate brand reputation. The empirical results provide evidence that both dimensions, implicit and explicit corporate brand reputation, have a crucial impact on the degree of attachment toward the brand.
\end{abstract}

\footnotetext{
K.-P. Wiedmann $(\varangle) \bullet$ S. Schmidt $\bullet$ S. Langner $\bullet$ L. Albertsen $\bullet$ E. Karampournioti Leibniz University of Hannover, Hannover, Germany e-mail: wiedmann@m2.uni-hannover.de; schmidt@m2.uni-hannover.de; langner@m2. uni-hannover.de; albertsen@m2.uni-hannover.de; karampournioti@m2.uni-hannover.de

P. Reiter eye square $\mathrm{GmbH}$, Berlin, Germany

e-mail: reiter@eye-square.com
} 